\title{
Vitamin E Protects against Thyroxine-Induced Acceleration of Lipid Peroxidation in Cardiac and Skeletal Muscles in Rats
}

\author{
Kohtaro Asayama, Kazushige Dobashi, Hidemasa Hayashibe, \\ and Kiyohiko KATO ${ }^{1}$ \\ Depertment of Pediatrics, Yamanashi Medical College, \\ Nakakoma-gun, Yamanashi 409-38, Japan
}

(Received March 24, 1989)

\begin{abstract}
Summary To determine whether vitamin E protects against thyroxineinduced oxidative stress in heart and soleus (slow oxidative) muscles, lipid peroxide (thiobarbituric acid-reactive substances) and antioxidant enzymes were measured in those tissues of hyperthyroid rats supplemented with vitamin $\mathrm{E}$. The rats were rendered hyperthyroid by the administration of L-thyroxine in their drinking water. In experiment (EXPT) I, $30 \mathrm{mg} / \mathrm{kg} / \mathrm{dose}$ of alpha-tocopheryl acetate was administered to the vitamin E-treated group. In EXPT II, the rats were fed a diet containing either $<1 \mathrm{IU} / \mathrm{kg}$ (deficient diet), $20 \mathrm{IU} / \mathrm{kg}$ (control E diet), or $500 \mathrm{IU} / \mathrm{kg}$ (high $\mathrm{E}$ diet) of vitamin $\mathrm{E}$ and hyperthyroidism was induced. In EXPT I, hyperthyroidism induced an increase in oxidative enzymes, mitochondrial superoxide dismutase and lipid peroxide level, and a decrease in cytosolic superoxide dismutase, glutathione peroxidase and catalase in both tissues. Vitamin $\mathrm{E}$ treatment inhibited the increase in lipid peroxide level totally in the heart and partially in the soleus, with minimal changes in the other biochemical indices studied. In EXPT II, the lipid peroxide level was markedly increased in both tissues of the vitamin E-deficient group, and decreased in those of the group fed high $\mathrm{E}$ diet. There were some adaptive changes in the levels of cytosolic superoxide dismutase, glutathione peroxidase, and catalase in response to vitamin $\mathrm{E}$ deficiency, whereas neither oxidative enzymes nor mitochondrial superoxide dismutase were altered. These results suggest that vitamin E protects against lipid peroxidation in hyperthyroid heart and skeletal muscle independently of the changes in oxidative enzymes and antioxidant enzymes.
\end{abstract}

Key Words hyperthyroidism, vitamin E, lipid peroxide, oxygen, superoxide, superoxide dismutase, glutathione peroxidase, catalase, heart, skeletal muscle

It has been postulated that accelerated mitochondrial respiratory electron

1 朝山光太郎, 土橋一重, 林辺英正, 加藤精彦 
transport brought about by a hypermetabolic state results in increased generation of superoxide at the site of ubiquinones (1). This species and other active oxygens generated by a subsequent cascade of free radical reactions can attack mitochondrial membrane and induce lipid peroxidation unless scavenged by either non-enzymatic antioxidants or antioxidant enzymes. The antioxidant enzymes comprise superoxide dismutase (SOD), glutathione peroxidase (GPX), and catalase (CAT). Animal cells have two forms of SOD. One contains manganese (MnSOD) and occurs predominantly in the mitochondrial matrix; the other contains copper and zinc (CuZnSOD) and is found uniformly throughout the nuclear and cytoplasmic matrix (2). GPX and CAT catalyze the reduction of hydrogen peroxide; the former also reduces organic hydroperoxide. Vitamin $\mathrm{E}$ is concentrated in the inner mitochondrial membrane where the respiratory electron transport system is located, and it is the major nonenzymatic chain-breaking antioxidant at that site (3).

We previously demonstrated a selective increase in the level of thiobarbituric acid-reactive substances (TBARS) in the heart and soleus (slow oxidative) muscles of hyperthyroid rats, and suggested the possible contribution of this oxidative injury to the development of thyrotoxic myopathy and myocardial dysfunction (4). The increase in TBARS was associated with an acceleration of mitochondrial oxidative metabolism and decreased activities of GPX and CAT(4).

The present study was designed to determine whether vitamin E administered simultaneously with thyroxine $\left(\mathrm{T}_{4}\right)$ can suppress the increase in TBARS in heart and soleus muscles. To further elucidate the interaction between antioxidant enzymes and vitamin $\mathrm{E}$ for protection against lipid peroxidation, the tissue levels of TBARS and CuZnSOD, MnSOD, GPX, and CAT in hyperthyroid rats fed special diets containing three different amounts of vitamin $\mathrm{E}$ were also studied.

\section{MATERIALS AND METHODS}

Animal treatment. In the first experiment (EXPT I), 5-week-old male Sprague-Dawley rats (Shizuoka Laboratory Animal Center, Shizuoka, Japan) were fed a standard chow. The euthyroid control group was given tap water. The remaining rats $\left(\mathrm{T}_{4}\right.$ and $\mathrm{T}_{4}+\mathrm{E}$ groups) were rendered hyperthyroid by the administration of $12 \mathrm{mg} /$ liter of L-thyroxine in their drinking water over a 4-week period, as described previously (4). The $\mathrm{T}_{4}+\mathrm{E}$ group was injected intraperitoneally with $30 \mathrm{mg} / \mathrm{kg} /$ dose of alpha-tocopheryl acetate $(1.11 \mathrm{IU} / \mathrm{mg})$ solubilized in $10 \%$ polyoxyethylene hydrogenated castor oil/ $10 \%$ propylene glycol buffered by sodium citrate (Eisai Co., Ltd., Tokyo). Vitamin E was injected once daily for the first 7 days, every other day for the second week, and then once every 3 days thereafter.

In the second experiment (EXPT II), 3-week-old male Sprague-Dawley rats were divided into 3 groups. They were fed a vitamin E-deficient diet containing $<1 \mathrm{IU} / \mathrm{kg}$ of vitamin $\mathrm{E}$, or the same diet supplemented with either $20 \mathrm{IU} / \mathrm{kg}$ (control $\mathrm{E}$ diet), or $500 \mathrm{IU} / \mathrm{kg}$ (high $\mathrm{E}$ diet) of vitamin E (Eisai Co., Ltd., Tokyo). The composition of the vitamin E-deficient diet was described previously (5). The rats 
were given tap water for 4 weeks, and then they were rendered hyperthyroid by the administration of $\mathrm{T}_{4}$ in their drinking water over a 3-week period.

The rats were killed under pentobarbital anesthesia $(50 \mathrm{mg} / \mathrm{kg})$, and their sera, heart, and bilateral soleus muscles were obtained.

Biochemical analyses. The tissue homogenate was prepared as described previously (4). The radioimmunoassays for rat MnSOD and CuZnSOD have been described (6). Cyto-chrome $c$ oxidase, fumarase, and glutathione peroxidase were assayed by methods described previously(7). Catalase activity was assayed spectrophotometrically $(8)$ in the samples of heart muscle, and polarographically (4) in the samples of soleus muscle. The activity was calculated using the first order rate constant for the former method, and the initial rate of $\mathrm{O}_{2}$ production for the latter. The tissue concentration of TBARS was assayed by the fluorimetric method of Yagi (9). Protein was measured by the technique of Lowry et al.(10). Alpha-tocopherol was determined utilizing high-performance liquid chromatography (11). Serum triiodothyronine $\left(\mathrm{T}_{3}\right)$ and $\mathrm{T}_{4}$ concentrations were determined with commercial RIA kits.

Statistics. The data are presented as the means \pm SE. Statistical significance was determined by the method of least significant difference, calculated after one-way analysis of variance.

\section{RESULTS}

Body weight, organ weight relative to body weight, $T_{3}, T_{4}$, and vitamin $E$

The initial and final body weights of the animals in both EXPT I and EXPT II, their heart and soleus weights relative to body weights, serum levels of $T_{3}$ and $\mathrm{T}_{4}$ are summarized in Table 1 . There was no difference between groups in the initial weight of the animals in either experiment, whereas the final body weight of the $\mathrm{T}_{4}$-treated rats was less than that of the euthyroid controls. Vitamin $\mathrm{E}$ either injected or supplemented in the diet did not appear to affect the growth of the animals. The heart was markedly hypertrophied in all $\mathrm{T}_{4}$-treated rats in both experiments. Vitamin E status, again, did not appear to modify this hypertrophy. Soleus weight relative to body weight was unaltered in EXPT I, while that in the vitamin E-deficient rats was slightly greater than that in the other groups in EXPT II. Serum levels of $\mathrm{T}_{3}$ and $\mathrm{T}_{4}$ in all $\mathrm{T}_{4}$-treated groups were well within the thyrotoxic range, and there was only a marginal difference in the $\mathrm{T}_{3}$ levels of the rats in EXPT II. Table 2 summarizes tissue level of alpha-tocopherol. The levels in both heart and soleus muscles in the $\mathrm{T}_{4}$-treated group in EXPT I were similar to those in their controls, while those in the $\mathrm{T}_{4}+\mathrm{E}$-treated group were markedly increased. The tissue levels of alpha-tocopherol in EXPT II reflected the vitamin E content in each respective test diet. The levels in the high $\mathrm{E}$ diet group in EXPT II were similar to those in the $\mathrm{T}_{4}+$ E-treated group. 


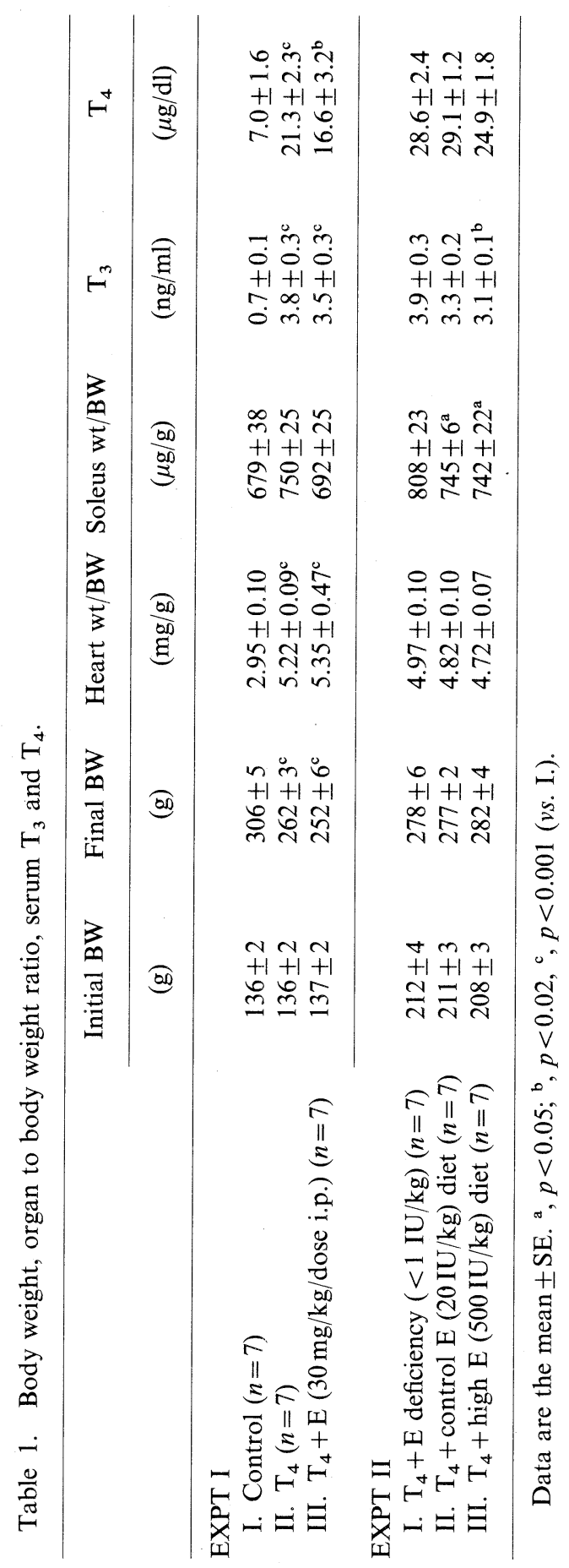


Table 2. Alpha-tocopherol level in heart and soleus muscles.

\begin{tabular}{|c|c|c|}
\hline & Heart & Soleus \\
\hline \multicolumn{3}{|l|}{ EXPT I } \\
\hline I. Control & $33.9 \pm 1.5$ & $15.5 \pm 0.6$ \\
\hline II. $\mathrm{T}_{4}$ & $34.7 \pm 0.4$ & $14.7 \pm 0.2$ \\
\hline III. $\mathrm{T}_{4}+\mathrm{E}$ & $56.0 \pm 2.8^{\mathrm{a}, \mathrm{b}}$ & $25.3 \pm 0.8^{\mathrm{a}, \mathrm{b}}$ \\
\hline \multicolumn{3}{|l|}{ EXPT II } \\
\hline I. $\mathrm{T}_{4}+\mathrm{E}$ deficiency & $2.3 \pm 0.2$ & $1.1 \pm 0.2$ \\
\hline II. $\mathrm{T}_{4}+$ control $\mathrm{E}$ diet & $25.0 \pm 0.1^{\mathrm{a}}$ & $10.4 \pm 1.5^{\mathrm{a}}$ \\
\hline III. $\mathrm{T}_{4}+$ high $\mathrm{E}$ diet & $61.5 \pm 2.7^{\mathrm{a}, \mathrm{b}}$ & $25.9 \pm 1.7^{\mathrm{a}, \mathrm{b}}$ \\
\hline
\end{tabular}

Data are the mean $\pm \mathrm{SE}$. Values are $\mu \mathrm{g} / \mathrm{g}$ tissue. ${ }^{\mathrm{a}} p<0.001(v s . \mathrm{I}),{ }^{\mathrm{b}}<0.001$ ( $\left.v s . \mathrm{II}\right)$.

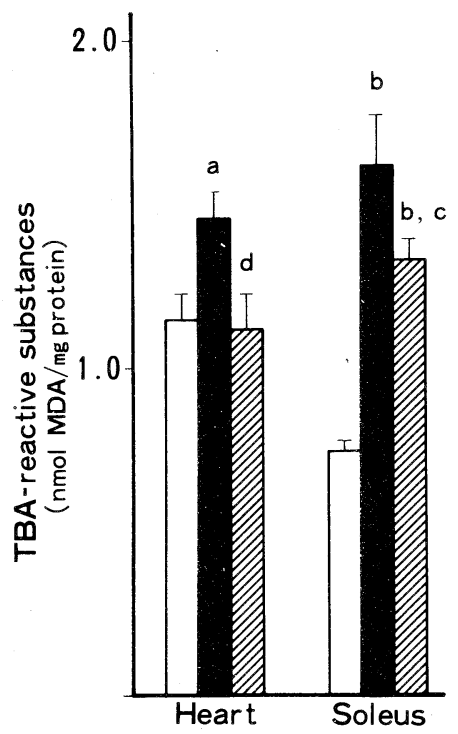

Fig. 1. Tissue levels of thiobarbituric acid (TBA)-reactive substances in EXPT I. Data are means of 7 observations. The brackets indicate SE. Open bars, controls; solid bars, $\mathrm{T}_{4}$-treated rats; hatched bars, $\mathrm{T}_{4}+\mathrm{E}$-treated rats. Statistical significance is as follows: a, $p<0.05$; and b, $p<0.001$ ( $v s$. controls); c, $p<0.05$; and $\mathrm{d}, p<0.02$ ( $v s$. $\mathrm{T}_{4}$-treated).

\section{Effect of $T_{4}$ and/or vitamin $E$ on enzymes and TBARS}

Table 3 lists the activities of cytochrome $c$ oxidase and fumarase as oxidative markers, SOD contents, and the activities of GPX and CAT in EXPT.I. The activity of cytochrome $c$ oxidase in both the heart and soleus muscles of the $\mathrm{T}_{4}$-treated group was increased, and was restored to control levels by vitamin $\mathrm{E}$ treatment. 


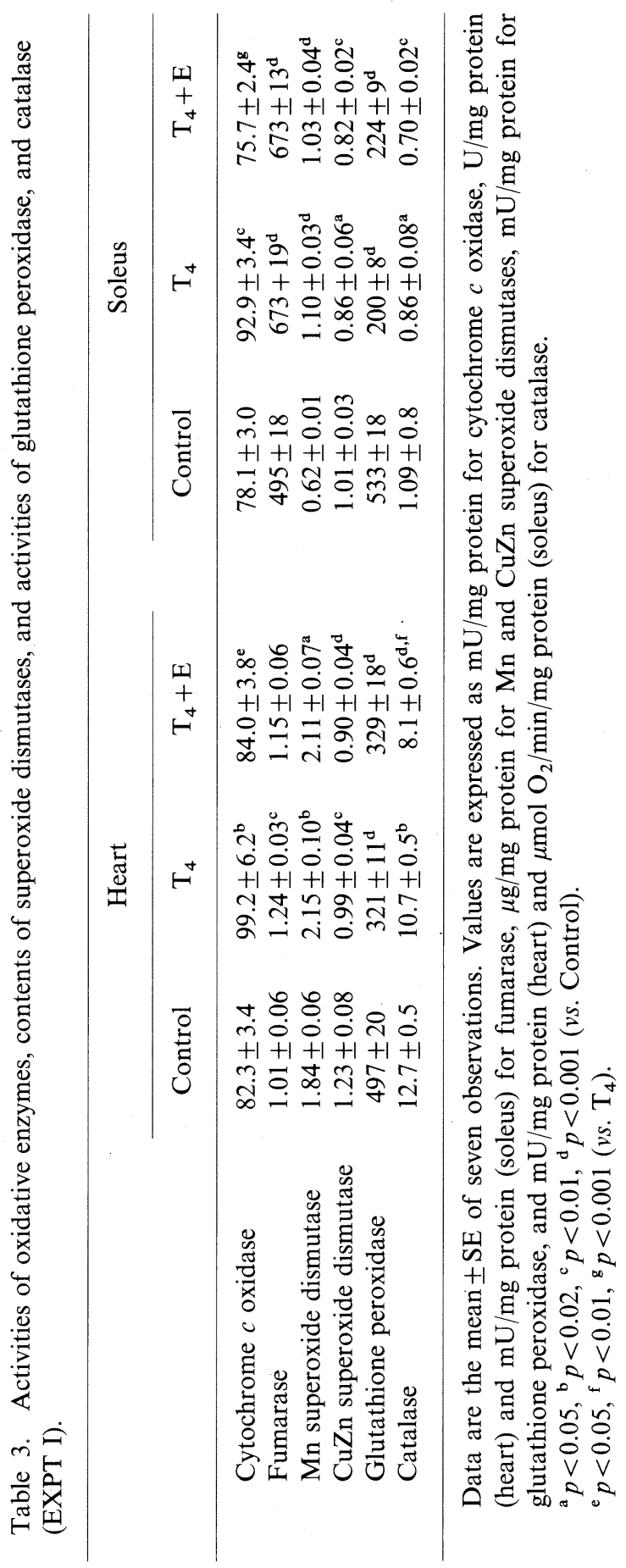




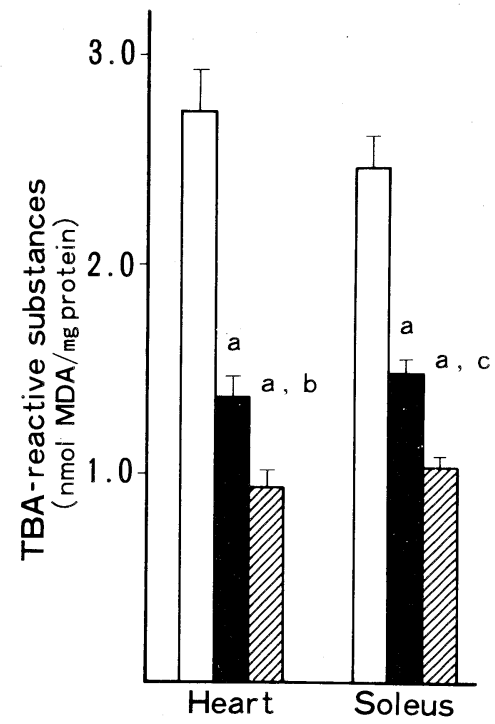

Fig. 2. Tissue levels of TBA-reactive substances in EXPT II. Data are means $\pm \mathrm{SE}$ $(n=7)$. Open bars: hyperthyroid rats fed a vitamin E-deficient $(<1 \mathrm{IU} / \mathrm{kg})$ diet; solid bars: hyperthyroid rats fed a control E $(20 \mathrm{IU} / \mathrm{kg})$ diet; hatched bars: hyperthyroid rats fed a high $\mathrm{E}(500 \mathrm{IU} / \mathrm{kg})$ diet. Statistical significance: $\mathrm{a}, p<0.001$ ( $v s$. E dificient); $\mathrm{b}, p<0.05$; and $\mathrm{c}, p<0.01$ ( $v s$. control E).

Fumarase activity was increased in the heart and soleus muscles of both the $\mathrm{T}_{4}$-treated and $\mathrm{T}_{4}+$ E-treated groups. Similarly, MnSOD was increased in both groups. On the other hand, CuZnSOD and GPX were decreased in both tissues of those groups. CAT activity was decreased in both tissues of the $\mathrm{T}_{4}$-treated groups, and was further decreased in the $\mathrm{T}_{4}+\mathrm{E}$-treated group. The TBARS levels in the heart and soleus muscles of the $\mathrm{T}_{4}$-treated group were increased, and vitamin $\mathrm{E}$ treatment suppressed the increase totally in the heart and partially in the soleus muscles (Fig. 1).

\section{Effect of vitamin E status on enzymes and TBARS in hyperthyroid tissues}

Table 4 lists the activities of oxidative enzymes, SOD contents, and the activities of GPX and CAT in EXPT II. Cytochrome $c$ oxidase activity in heart and soleus muscles was not significantly different among the groups. Similarly, fumarase and MnSOD in both tissues were also unaltered. CuZnSOD levels in the heart were unaltered, while that in the E-deficient soleus was significantly higher than those in the control $\mathrm{E}$ and high $\mathrm{E}$ soleus. In both tissues, the GPX was higher in the E-deficient, and lower in the high E groups, that in the controls. Similarly, the heart CAT was higher in the E-deficient, and lower in the high E groups, than in the controls. The CAT in the E-deficient soleus was higher than that in the high $\mathrm{E}$ soleus, but similar to that in the controls. A marked change was observed in the 


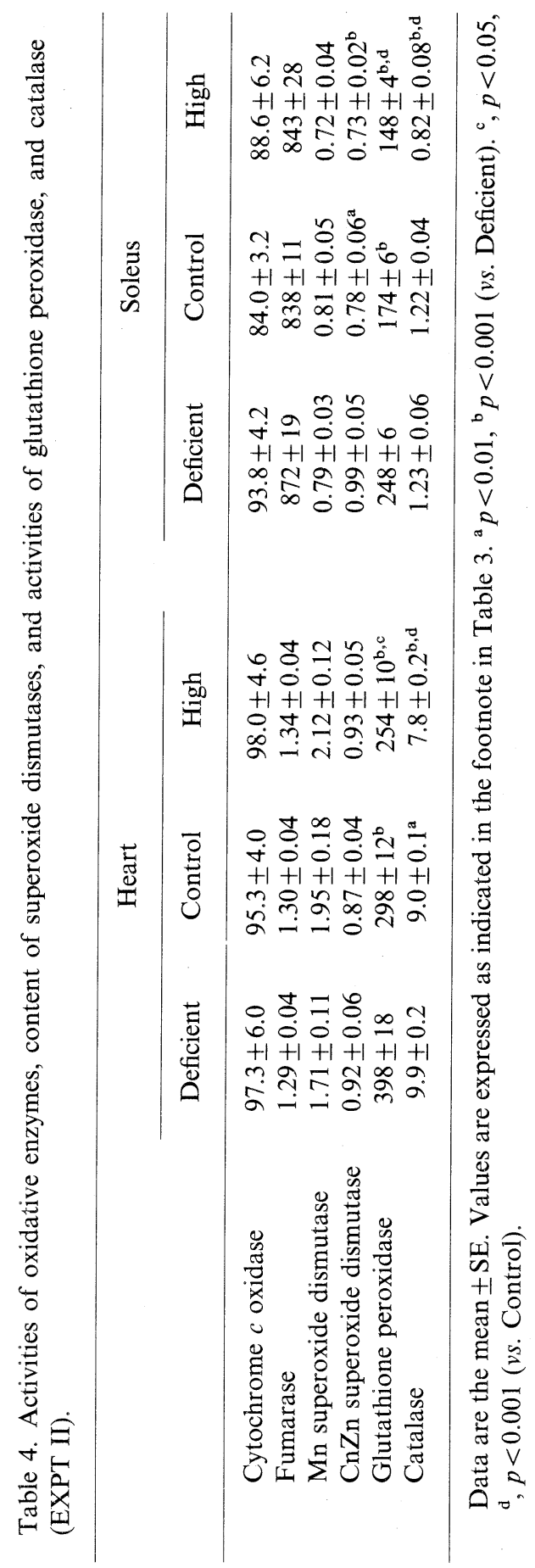

J. Nutr. Sci. Vitaminol. 
TBARS levels in EXPT II (Fig. 2). The TBARS level in the E-deficient heart was twice as high as in the controls, and 3 times as high as in the high E hearts. Similarly, the soleus TBARS was higher in the E-deficient and lower in the high E groups than in the controls.

\section{DISCUSSION}

In the hyperthyroid heart and soleus muscles, mitochondrial oxidative enzymes were increased, with a parallel increase in MnSOD. On the other hand, other antioxidant enzymes were decreased, and lipid peroxide was increased. These results confirmed the changes observed in our previous study (4). Vitamin E injected as a large dose in hyperthyroid animals significantly protected against acceleration of lipid peroxidation in muscular tissues. This was associated with only a minimal change in the levels of antioxidant enzymes. The suppression of lipid peroxidation in hyperthyroid muscular tissues by vitamin $\mathrm{E}$ was also confirmed in animals in which dietary vitamin $\mathrm{E}$ was fortified. The change in vitamin $\mathrm{E}$ status affected the tissue levels of antioxidant enzymes to a certain extent, but we could find no evidence that vitamin $\mathrm{E}$ potentiated their actions in the present study.

Neradilova et al. have reported that the alpha-tocopherol concentration was increased in heart and skeletal muscles of hyperthyroid rats (12). But they also reported that this was a transient phenomenon(13). In fact, alpha-tocopherol concentrations in the hyperthyroid tissues in EXPT I were similar to those in the controls. Thus, the increase in lipid peroxide level in the hyperthyroid tissues observed here is not due to secondary change in vitamin E status, but presumably is due to the decrease in the second line antioxidant enzyme (i.e. GPX and CAT).

Several investigators have reported a therapeutic function for vitamin $\mathrm{E}$ in experimental hyperthyroidism. Vitamin $\mathrm{E}$ ameliorated both reduction in cardiac glycogen concentration (14) and acceleration of oxidative phosphorylation in the brain (15) of hyperthyroid rats. In the present study, vitamin E suppressed the cytochrome $c$ oxidase activity in hyperthyroid rats when administered intraperitoneally, but this was not the case when it was supplemented in the diet. Fumarase activity was not affected by vitamin E injection. Furthermore, the tissue levels of alpha-tocopherol in the $\mathrm{T}_{4}+\mathrm{E}$ group in EXPT I did not exceed those in the high E group EXPT II. Thus, the suppression of cytochrome $c$ oxidase in $\mathrm{T}_{4}+$ E-treated group in EXPT I cannot be explained by the presence of high levels of $\alpha$-tocopherol. The results of EXPT II indicate that the suppression of lipid peroxidation was independent of the activity of cytochrome $c$ oxidase.

The reported effects of vitamin $\mathrm{E}$ deficiency on tissue levels of antioxidant enzymes have not been uniform in various tissues, because of differences in various factors such as animal species, severity and duration of the deficiency, and the organs studied. We previously observed that levels of neither the two SODs, GPX, nor CAT in heart and skeletal muscle of rats were affected in a mild vitamin $\mathrm{E}$ dificiency induced by feeding the deficient diet from 10 weeks of age (16). In that 
study, MnSOD in the pancreatic islets was decreased in vitamin E-deficient animals. Masugi et al. observed no change in SOD, GPX, or CAT in rat liver (17), but Suga et al. reported that CAT was decreased in the same tissue (18). Vitamin E deficiency induced a decrease in mitochondrial SOD in rabbit heart as measured by an indirect activity assay (19). Yang et al. observed an inverse relationship between GPX activity and vitamin E staus in rat liver (20), as was found in the muscles in EXPT II. Such a change may be an adaptive response to the alteration in oxidant-antioxidant balance.

Several previous observations have supported a close relationship between the glutathione redox system and vitamin $\mathrm{E}$ as cell defense mechanisms. Mutual dependence of the protection against peroxidative stress has been shown $(21,22)$. It has been also reported that the actions of vitamin $\mathrm{E}$ and the glutathione redox system compensate for each other in certain experimental models in which one of their activities is low $(23,24)$. In the present hyperthyroid muscles, vitamin $\mathrm{E}$ appeared to compensate for the low activity of the glutathione redox system in oxidative stress. There were some increases in GPX activity and in other antioxidant enzymes in response to vitamin E deficiency, whereas they appeared to provide no protection against acceleration of lipid peroxidation.

Superoxide production has been reported to be increased in heart mitochondria of vitamin E-deficient animals (19). It has been postulated that vitamin $\mathrm{E}$ is an essential component in heart (25) and skeletal muscles(26) for the protection of mitochondria against peroxidative damage. It is conceivable that vitamin $\mathrm{E}$ is consumed more rapidly in hyperthyroid muscles in which mitochondrial respiratory electron tranport and, in turn, superoxide generation are accelerated than in euthyroid muscles. The present results indicate that vitamin $\mathrm{E}$ deficiency aggravates and supplementation inhibits the early biochemical change (i.e. the acceleration of lipid peroxidation) predisposing to thyrotoxic myopathy and myocardial dysfunction. This implies that an adequate intake of vitamin $\mathrm{E}$ would be beneficial for the prevention of muscle damage in hyperthyroid subjects.

The authors gratefully acknowledge Mr. Yukou Kayamoto of Eisai Co., Ltd., Tokyo, for providing vitamin $\mathrm{E}$ preparations and special diets, and for the determination of tissue alpha-tocopherol level. They also wish to thank Satoru Kojika and Shinichi Shimomura for their technical assistance

This work was supported in part by Grant-in-Aid 62770644 from the Ministry of Education, Science and Culture of Japan and a Grant-in-Aid from the Naito Foundation.

\section{REFERENCES}

1) Boveris, A., Cadenas, E., and Shoppani, A. O. M. (1976): Role of ubiquinone in the mitochondrial generation of hydrogen peroxide. Biochem. J., 156, 435-444.

2) Slot, J. W., Geuze, H. J., Freeman, B. A., and Crapo, J. D. (1986): Intracellular localization of the copper-zinc and manganese superoxide dismutases in rat liver parenchymal cells. Lab. Invest., 55, 363-371. 
3) Gohil, K., Rothfuss, L., Lang, J., and Packer, L. (1987): Effect of exercise training on tissue vitamin E and ubiquinone content. J. Appl. Physiol., 63, 1638-1641.

4) Asayama, K., Dobashi, K., Hayashibe, H., Megata, Y., and Kato, K. (1987): Lipid peroxidation and free radical scavengers in thyroid dysfunction in the rat: A possible mechanism of injury to heart and skeletal muscle in hyperthyroidism. Endocrinology, 121, 2112-2118.

5) Mino, M., Kasugai, O., and Shimizu, T. (1985): Red blood cell tocopherol and liver tocopherol in hyperlipidemic rats as compared with plasma tocopherol. Lipids, 20, 488-491.

6) Asayama, K., and Burr, I. M. (1985): Rat superoxide dismutase: purification, labeling, immunoassay, and tissue concentration. J. Biol. Chem., 260, 2212-2217.

7) Asayama, K., Dettbarn, W. D., and Burr, I. M. (1986): Differential effect of denervation on free-radical scavenging enzymes in slow and fast muscle of rat. J. Neurochem., 46, 604-609.

8) Thomson, J. F., Nance, S. L., and Tollaksen, S. L. (1978): Spectrophotometric assay of catalase with perborate as substrate. Proc. Soc. Exp. Biol. Med., 157, 33-35.

9) Yagi, K. (1984): Assay of modes of biological damage imposed by $\mathrm{O}_{2}$ and reduced species. A Lipid peroxidation, in Methods in Enzymology, Vol. 105, ed. by Packer, L., Academic Press, Orlando, pp. 328-331.

10) Lowry, O. H., Rosebrough, N. J., Farr, A. L., and Randall, A. J. (1951): Protein measurement with the Folin phenol reagent. J. Biol. Chem., 193, 265-275.

11) Abe, K., Yuguchi, Y., and Katsui, G. (1975): Quantitative determination of tocopherols by high-speed liquid chromatography. J. Nutr. Sci. Vitaminol., 21, 183-188.

12) Neradilova, M., Hruba, F., Novakova, V., and Blahosova, I. (1973): Investigations of the relationship between thyroid function and alpha-tocopherol concentration of serum and in some organs of the rat. Int. J. Vitam. Nutr. Res., 43, 283-290.

13) Hruba, F., Neradilova, M., Movakova, V., and Blahosova, I. (1976): Effect of hyper- and hypothyroidism on the alpha-tocopherol concentration in serum and some organs of growing rats. Int. J. Vitam. Nutr. Res., 46, 381-389.

14) Postelnicu, D. (1972): Action of an antioxidant substance (alpha-tocopherol) on the myocardium of rats treated with thyroxine. Stud. Cercet. Endocrinol., 23, 175-181.

15) Uzebekova, D. G. (1970): Effect of alpha-tocopherol, adenosine triphosphoric acid, nerobolil and apilac on the oxidative phosphorylation in the brain hemispheres in thyroxine poisoning. Farmakol. Toksikol., 33, 451-460.

16) Asayama, K., Kooy, N. W., and Burr, I. M. (1986): Effect of vitamin E deficiency and selenium deficiency on insulin secretory reserve and free radical scavenging systems in islets.J. Lab. Clin. Med., 107, 459-464.

17) Masugi, F., and Nakamura, T. (1976): Effect of vitamin E deficiency on the level of superoxide dismutase, glutathione peroxidase, catalase and lipid peroxide in rat liver. Int. J. Vitam Nutr. Res., 46, 187-191.

18) Suga, T., Watanabe, T., Matsumoto, Y., and Horie, S. (1984): Effects of long-term vitamin E deficiency and restoration on rat hepatic peroxisomes. Biochim. Biophys. Acta, 794, 218-224.

19) Flamigni, F., Guarnieri, C., Toni, R., and Caldarera, C. M. (1982): Effect of oxygen radicals on heart mitochondrial function in alpha-tocopherol deficient rabbits. Int. J. Vitam. Nutr. Res., 52, 402-406.

20) Yang, N. Y. J., MacDonald, I.B., and Desai, I. D. (1976): Vitamin E supplementation and glutathione peroxidase activity. Proc. Soc. Exp. Biol. Med., 151, 770-774. 
21) Reddy, C. C., Scholz, R. W., Thomas, C. E., and Massoro, E. J. (1982): Vitamin E dependent reduced glutathione inhibition of rat liver microsomal lipid peroxidation. Life Sci., 31, 571-576.

22) Pascoe, G. A., Fariss, M. W., Olafsdottir, K., and Reed, D. J. (1987): A role of vitamin $\mathrm{E}$ in protection against cell injury. Eur. J. Biochem., 166, 241-247.

23) Yoshida, M., Fukunaga, T., Iwami, K., and Yasumoto, K. (1984): Variation of glutathione level and synthesis activity in chick liver due to selenium and vitamin $\mathrm{E}$ deficiency. J. Biochem., 96, 1391-1397.

24) Reed, D. J., Pascoe, G. A., and Olafsdottir, K. (1987): Some aspects of cell defense mechanisms of glutathione and vitamin E during cell injury. Arch. Toxicol., suppl., 11, 34-38.

25) Ferrari, R., Ceconi, C., Curello, S., Cargnoni, A., Condorelli, E., and Raddino, R. (1985): Role of oxygen in myocardial ischemic and reperfusion damage: effect of alpha-tocopherol. Acta Voitaminol. Enzymol., 7 suppl, 61-70.

26) Jackson, M. J. (1987): Muscle damage during exercise: possible role of free radicals and protective effect of vitamin E. Proc. Nutr. Soc., 46, 77-80. 